\title{
INDIVISIBLE LABOR AND THE BUSINESS CYCLE
}

\author{
Gary D. HANSEN* \\ University of California, Santa Barbara, CA 93106, USA
}

\begin{abstract}
A growth model with shocks to technology is studied. Labor is indivisible, so all variability in hours worked is due to fluctuations in the number employed. We find that, unlike previous equilibrium models of the business cycle, this economy displays large fluctuations in hours worked and relatively small fluctuations in productivity. This finding is independent of individuals" willingness to substitute leisure across time. This and other findings are the result of studying and comparing summary statistics describing this economy, an economy with divisible labor, and post-war U.S. time series.
\end{abstract}

\section{Introduction}

Equilibrium theories of the business cycle, such as Kydland and Prescott (1982) or Lucas (1977), have been criticized for failing to account for some important labor market phenomena. These include the existence of unemployed workers, fluctuations in the rate of unemployment, and the observation that fluctuations in hours worked are large relative to productivity fluctuations. Equilibrium models have also been criticized for depending too heavily on the willingness of individuals to substitute leisure across time in response to wage or interest rate changes when accounting for the last observation. This criticism is based at least partially on the fact that micro studies using panel data on hours worked by individuals have not detected the intertemporal substitution necessary to explain the large aggregate fluctuations in hours worked [see Ashenfelter (1984)].

In this paper, a simple one-sector stochastic growth model with shocks to technology is constructed in which there is high variability in the number employed and total hours worked even though individuals are relatively unwilling to substitute leisure across time. The model differs from similar models, such as Kydland and Prescott (1982), in that a non-convexity (indivisible labor) is introduced. Indivisible labor is modeled by assuming that individ-

\footnotetext{
*This paper is part of my doctoral dissertation written while a student at the University of Minnesota. I have benefited from conversations with many people including Robert King, Thomas Sargent, Christopher Sims, Neil Wallace, Sumru Altug, Patrick Kehoe, Ramon Marimon, Ian Bain, and Rody Manuelli. I owe my greatest debt, however, to my advisor, Edward Prescott. I wish to also acknowledge the Federal Reserve Bank of Minneapolis which has provided support for this research. All errors, of course, are mine.
} 
uals can either work some given positive number of hours or not at all - they are unable to work an intermediate number of hours. This assumption is motivated by the observation that most people either work full time or not at all. Therefore, in my model, fluctuations in aggregate hours are the result of individuals entering and leaving employment rather than continuously employed individuals adjusting the number of hours worked, as in previous equilibrium models. This is consistent with an important feature of U.S. post-war data: most fluctuation in aggregate hours worked is due to fluctuation in the number employed as opposed to fluctuation in hours per employed worker. This is a fact that previous equilibrium theories have not tried to account for. ${ }^{1}$

Existing equilibrium models have also failed to account for large fluctuations in hours worked along with relatively small fluctuations in productivity (or the real wage). Prescott (1983), for example, finds that for quarterly U.S. time series, hours worked fluctuates about twice as much (in percentage terms) as productivity. In this paper it is shown that an economy with indivisible labor exhibits very large fluctuations in hours worked relative to productivity. This stands in marked contrast to an otherwise identical economy that lacks this non-convexity. In this economy hours worked fluctuates about the same amount as productivity. ${ }^{2}$

Equilibrium theories of the business cycle have typically depended heavily on intertemporal substitution of leisure to account for aggregate fluctuations in hours worked. ${ }^{3}$ The willingness of individuals to substitute intertemporally is measured by the elasticity of substitution between leisure in different time periods implied by an individual's utility function. However, the theory developed here is able to account for large aggregate fluctuations in hours worked relative to productivity without requiring that this elasticity be large. This follows because the utility function of the 'representative agent' in our model implies an elasticity of substitution between leisure in different periods that is infinite. ${ }^{4}$ This result does not depend on the elasticity of substitution implied by the preferences of the individuals who populate the economy. Thus, the theory presented here is in principle consistent with the low estimates of this elasticity found from studying panel data [see Altonji (1984) or MaCurdy (1981)].

\footnotetext{
${ }^{1}$ The fact that existing equilibrium models are inconsistent with this observation has been stressed by Heckman (1983) and Coleman (1984).

${ }^{2}$ Kydland and Prescott (1982) attempt to explain the above fact by including past leisure as an argument in the individual's utility function so as to enhance the intertemporal substitution response to a productivity shock. However, even after introducing this feature, Kydland and Prescott were still unable to account for this observation.

${ }^{3}$ This is true for the technology shock theories, such as Kydland and Prescott's (1982), as well as the monetary shock theories of Lucas and Barro [see Lucas (1977)].

${ }^{4}$ In this model there is a crucial distinction between the utility function of the 'representative agent' and the utility function of an individual or household.
} 
The paper is divided as follows: The next section provides a more detailed explanation and motivation of the indivisible labor assumption. In section 3 the artificial economies to be studied are constructed. The first is a standard stochastic growth model where labor is divisible, and the second introduces indivisible labor to that economy. The second economy is a stochastic growth version of a static general equilibrium model developed by Rogerson (1984). Lotteries are added to the consumption set (following Rogerson) which makes it possible to study a competitive equilibrium by solving a representative agent problem, as in Lucas and Prescott (1971). The addition of the lotteries also implies that the firm is providing full unemployment insurance to the workers.

The fourth section explains how the equilibrium decision rules and laws of motion are calculated, as well as how the parameter values used when simulating the model were chosen. Since the representative agent's problem is not one for which a closed form solution is available, in order to calculate decision rules a quadratic approximation of this problem is derived using the method described in Kydland and Prescott (1982). These equilibrium decision rules are a set of stochastic difference equations from which the statistical properties of the time series generated by the artificial economies can be determined. The statistics studied are a set of standard deviations and correlations discussed in section 5. In this section, the statistics computed using the artificial time series are compared to the same statistics computed using U.S. time series. Some concluding remarks are contained in section 6 .

\section{Motivation}

Existing equilibrium theories of the business cycle analyze individuals who are free to adjust continuously the number of hours worked (the 'intensive margin') and who are always employed. There are no individuals entering or leaving employment (the 'extensive margin'). However, the extensive margin seems important for explaining some aspects of labor supply at both the micro and macro levels. Heckman and MaCurdy (1980), for example, discuss the importance of the extensive margin for explaining female labor supply. At the aggregate level, over half of the variation in total hours worked is due to variation in the number of individuals employed rather than variation in average hours worked by those employed. Consider the following decomposition of variance involving quarterly data:

$$
\operatorname{var}\left(\log H_{t}\right)=\operatorname{var}\left(\log h_{t}\right)+\operatorname{var}\left(\log N_{t}\right)+2 \operatorname{cov}\left(\log h_{t}, \log N_{t}\right),
$$

where $H_{t}$ is total hours worked, $h_{t}$ is average hours worked, and $N_{t}$ is the number of individuals at work, where all variables are deviations from trend. ${ }^{s}$

\footnotetext{
${ }^{5}$ The data used for this analysis is available from the Bureau of Labor Statistics' Labstat data tape. The series I used were collected from households using the Current Population Survey. For a description of the detrending method, see footnote 18.
} 
Using this decomposition, $55 \%$ of the variance of $H_{t}$ is due to variation in $N_{r}$, while only $20 \%$ of this variance can be directly attributed to $h_{t}$. The remainder is due to the covariance term. ${ }^{6}$

Most people either work full time or not at all. This might be ascribed to the presence of non-convexities either in individual preferences for leisure or in the technology. For example, the technology may be such that the marginal productivity of an individual's work effort is increasing during the first part of the workday or workweek, and then decreasing later on. That is, the individual faces a production function which is convex at first and then becomes concave. This could be due to individuals requiring a certain amount of 'warm up' time before becoming fully productive. Such a technology could induce individuals to work a lot or not at all.

Another possibility is that the non-convexity is a property of individuals' preferences. If the utility function exhibited decreasing marginal utility of leisure at low levels of leisure and increasing marginal utility at higher levels, individuals would tend to choose a low level of leisure (work a lot) or use their entire time endowment as leisure (not work at all). These preferences may be interpreted as 'indirect' preferences which reflect costs associated with working each period, such as driving a long distance to work or enduring the hassle of putting on a suit and tie. Bearing these fixed costs makes an individual less likely to choose to work only half a day.

In this paper the non-convexity is assumed to be a property of preferences. ${ }^{7}$ However, to make the model tractable, the non-convexity introduced - indivisible labor - is an extreme version of the non-convexity described above. Individuals are assumed to have preferences that are defined only at two levels of leisure - one level corresponding to working full time and the other corresponding to not working at all. This is modeled by assuming that the consumption possibilities set consists of only two levels of leisure. This assumption implies that an individual can only adjust along the extensive margin.

Of course fluctuations along both the extensive and intensive margins are observed in the actual economy, as the above evidence indicates. However, by studying two economies - one that exhibits fluctuations only along the intensive margin and another with fluctuations only along the extensive margin - we can determine the importance of non-convexities for explaining labor variability in business cycles. If it turns out that both economies exhibit the same cyclical behavior, then it seems likely that a model that incorporated both margins would also exhibit similar behavior. In fact, non-convexities of this

\footnotetext{
${ }^{6}$ Coleman (1984) comes to a similar conclusion using establishment data.

${ }^{7}$ One advantage of modeling the non-convexity as a feature of the technology is that it would likely explain why part-time workers are paid less than full-time vorkers, in addition to accounting for features of the data discussed in this paper.
} 
sort could probably be safely abstracted from when studying business cycle phenomena. However, it happens that the two models have very different implications and that the non-convexity improves our ability to account for U.S. aggregate time series data.

\section{Two economies}

\subsection{A one-sector stochastic growth model with divisible labor}

The economy to be studied is populated by a continuum of identical infinitely lived households with names on the closed interval $[0,1]$. There is a single firm with access to a technology described by a standard Cobb-Douglas production function of the form

$$
f\left(\lambda_{t}, k_{t}, h_{t}\right)=\lambda_{t} k_{t}^{\theta} h_{t}^{1-\theta},
$$

where labor $\left(h_{t}\right)$ and accumulated capital $\left(k_{t}\right)$ are the inputs and $\lambda_{t}$ is a random shock which follows a stochastic process to be described below. Agents are assumed to observe $\lambda$, before making any period $t$ decisions. The assumption of one firm is made for convenience. Since the technology displays constant returns to scale - implying that firms make zero profit in equilibrium - the economy would behave the same if there were many firms.

Output, which is produced by the firm and sold to the households, can either be consumed $\left(c_{t}\right)$ or invested $\left(i_{t}\right)$, so the following constraint must be satisfied:

$$
c_{t}+i_{t} \leq f\left(\lambda_{t}, k_{t}, h_{t}\right) .
$$

The law of motion for the capital stock is given by

$$
k_{t+1}=(1-\delta) k_{t}+i_{t}, \quad 0 \leq \delta \leq 1,
$$

where $\delta$ is the rate of capital depreciation. The stock of capital is owned by the households who sell capital services to the firm.

The technology shock is assumed to follow a first-order Markov process. In particular, $\lambda$, obeys the following law of motion:

$$
\lambda_{t+1}=\gamma \lambda_{t}+\varepsilon_{t+1},
$$

where the $\varepsilon_{f}$ 's are iid with distribution function $F$. This distribution is assumed to have a positive support with a finite upper bound, which guarantees that output will always be positive. By requiring $F$ to have mean $1-\gamma$, the unconditional mean of $\lambda_{t}$ is equal to 1 .

This technology shock is motivated by the fact that in post-war U.S. time series there are changes in output (GNP) that can not be accounted for by 
changes in the inputs (capital and labor). We follow Solow (1957) and Kydland and Prescott (1982) in interpreting this residual as reflecting shocks to technology.

Households in this economy maximize the expected value of $\sum_{1 \rightarrow 0}^{\infty} \beta^{\prime} u\left(c_{t}, l_{t}\right)$, where $0<\beta<1$ is the discount factor and $c$, and $l$, are consumption and leisure in period $t$, respectively. The endowment of time is normalized to be one, so $l_{t}=1-h_{t}$. Utility in period $t$ is given by the function

$$
u\left(c_{t}, l_{t}\right)=\log c_{t}+A \log l_{t}, \quad A>0 .
$$

We now have a complete specification of the preferences, technology, and stochastic structure of a simple economy where individuals are able to supply any level of employment in the interval $[0,1]$. Each period three commodities are traded: the composite output commodity, labor, and capital services. It is possible to consider only this sequence of spot markets since there is no demand for intertemporal risk sharing which might exist if households were heterogeneous.

Households solve the following problem, where $w_{t}$ is the wage rate at time $t$ and $r_{r}$ is the rental rate of capital:

$$
\max E \sum_{t=0}^{\infty} \beta^{t} u\left(c_{t}, 1-h_{t}\right), \text { given } k_{0} \text { and } \lambda_{0},
$$

subject to

$$
c_{t}+i_{t} \leq w_{t} h_{t}+r_{t} k_{t} \text { and (3). }
$$

Agents are assumed to make period $t$ decisions based on all information available at time $t$ (which includes $r_{t}$ and $w_{f}$ ). They have rational expectations in that their forecasts of future wages and rental rates are the same as those implied by the equilibrium laws of motion. The first-order conditions for the firm's profit maximization problem imply that the wage and rental rate each period are equal to the marginal productivity of labor and capital, respectively.

Since there are no externalities or other distortions present in this economy, the equal-weight Pareto optimum can be supported as a competitive equilibrium. Since agents are homogeneous, the equal-weight Pareto optimum is the solution to the problem of maximizing the expected welfare of the representative agent subject to technology constraints. This problem is the following:

$$
\max \mathrm{E} \sum_{t=0}^{\infty} \beta^{\prime} u\left(c_{t}, 1-h_{t}\right), \text { given } k_{0} \text { and } \lambda_{0},
$$

subject to

$$
\text { (1)-(4) and } \varepsilon_{t} \sim \text { c.d.f. } F \text {. }
$$


The state of the economy in period $t$ is described by $k_{t}$ and $\lambda_{r}$. The decision variables are $h_{t}, c_{t}$, and $i_{t}$.

This problem can be solved using dynamic programming techniques. ${ }^{8}$ This requires finding the unique continuous function $V: S \rightarrow \mathbb{R}$ (where $S$ is the state space) that satisfies Bellman's equation (primes denote next period values)

$$
V(k, \lambda)=\max \left\{u(c, 1-h)+\beta E\left[V\left(k^{\prime}, \lambda^{\prime}\right) \mid \lambda\right]\right\},
$$

where the maximization is over $c$ and $h$ and is subject to the same constraints as (7). The value function, $V(k, \lambda)$, is the maximum obtainable expected return over all feasible plans. It turns out that since the utility function is concave and the constraint set convex, the value function is also concave. This implies that the problem ( 8$)$ is a standard finite-dimensional concave programming problem.

Unfortunately, this problem is not one which can be solved analytically. There is no known explicit functional form for the value function, $V$. In principle this problem could be solved using numerical methods [see Bertsekas (1976)], but a cheaper method - which does enable one to solve for closed form decision rules - is to approximate this problem by one which consists of a quadratic objective and linear constraints, as in Kydland and Prescott (1982). This method will be explained briefly in section 4 .

\subsection{An economy with indivisible labor}

The assumption of indivisible labor will now be added to the above stochastic growth model. This will give rise to an economy where all variation in the labor input reflects adjustment along the extensive margin. This differs from the economy described above where all variation in the labor input reflects adjustment along the intensive margin. In addition, the utility function of the 'representative agent' for this economy will imply an elasticity of substitution between leisure in different periods that is infinite and independent of the elasticity implied by the utility function of the individual households.

Indivisibility of labor is modeled by restricting the consumption possibilities set so that individuals can either work full time, denoted by $h_{0}$, or not at all. ${ }^{9}$

\footnotetext{
${ }^{8}$ For a detailed presentation of dynamic programming methods, see Lucas, Prescott and Stokey (1984).

${ }^{9}$ This is consistent with the interpretation given in section 2. An alternative interpretation of indivisible labor assumes that households can work one of two possible (non-zero) number of hours, $h_{1}$ or $h_{2}$. This interpretation is consistent with an environment where each household consists of two individuals, at least one of whom works at all times. When only one member works, the household is working $h_{1}$ hours, and when both members work the household is working $h_{2}$ hours.
} 
In order to guarantee [using Theorem 2 of Debreu (1954)] that the solution of the representative agent's problem can be supported as a competitive equilibrium, it is necessary that the consumption possibilities set be convex. However, if one of the commodities traded is hours worked (as in the above model), the consumption possibilities set will be non-convex. To circumvent this problem, we convexify the consumption possibilities set by requiring individuals to choose lotteries rather than hours worked, following Rogerson (1984). ${ }^{10}$ Thus, each period, instead of choosing manhours, households choose a probability of working, $\alpha_{r,}{ }^{11}$ A lottery then determines whether or not the household actually works. After changing the economy in this manner, we make it possible for the competitive equilibrium to be derived by solving a concave programming problem, just as for the economy with divisible labor.

The new commodity being introduced is a contract between the firm and a household that commits the household to work $h_{0}$ hours with probability $\alpha_{t}$. The contract itself is being traded, so the household gets paid whether it works or not. Therefore, the firm is providing complete unemployment insurance to the workers. Since all households are identical, all will choose the same contract - that is, the same $\alpha_{r}$. However, although households are ex ante identical, they will differ ex post depending on the outcome of the lottery: a fraction $\alpha_{1}$ of the continuum of households will work and the rest will not. ${ }^{12}$

Using (5), expected utility in period $t$ is given by $\alpha_{1}\left(\log c_{t}+A \log \left(1-h_{0}\right)\right)+$ $\left(1-\alpha_{t}\right)\left(\log c_{t}+A \log 1\right){ }^{13}$ This simplifies to the following function $U: \mathbb{R}_{+}$ $\times[0,1] \rightarrow \mathbb{R}$,

$$
U\left(c_{t}, \alpha_{t}\right)=\log c_{t}+A \alpha_{t} \log \left(1-h_{0}\right) .
$$

${ }^{10}$ In Rogerson's paper, a static economy with indivisible labor is studied and lotteries are introduced to solve the problem introduced by this non-convexity. Readers may wish to consult Rogerson's paper for a rigorous general equilibrium formulation of this type of model.

${ }^{11}$ Adding lotteries to the consumption set increases the choices available to households when labor is indivisible. If lotteries were not available, houscholds would only be able to choose to not work (corresponding to $\alpha=0$ ) or to work $h_{0}$ (corresponding to $\alpha=1$ ). Therefore, adding lotteries can only make individuals better off.

${ }^{12}$ The lottery involves drawing a realization of a random variable $z$, from the uniform distribution on $[0,1]$. Each individual $i \in[0,1]$ is now 'renamed' according to the following rule:

$$
\begin{aligned}
x_{1}(i, z) & \equiv i+z_{1} & & \text { if } i+z_{1} \leq 1, \\
& \equiv i+z_{1}-1 & & \text { otherwise. }
\end{aligned}
$$

The amount worked by agent $x$ in period $t$ is equal to

$$
\begin{aligned}
h_{t}(x) & =0 & \text { if } & x_{t}(i, z) \leq 1-\alpha_{t}, \\
& =h_{0} & \text { if } & x_{t}(i, z)>1-\alpha_{t} .
\end{aligned}
$$

This provides a mechanism for dividing the continuum of agents into two subsets, one where each individual works zero hours and another where individuals work $h_{0}$. The first will have measure $\left(1-\alpha_{t}\right)$ and the other measure $\alpha_{t}$. This follows from the easily verified fact that $\operatorname{Prob}\left[x_{t}(i, z) \leq\right.$ $\left.1-\alpha_{t}\right]$ is equal to $l-\alpha_{t}$ for each $i$.

${ }^{13}$ This uses the fact that, since preferences are separable in consumption and leisure, the consumption level chosen in equilibrium is independent of whether the individual works or not. 
Since a fraction $\alpha_{t}$ of households will work $h_{0}$ and the rest will work zero, per capita hours worked in period $t$ is given by

$$
h_{t}=\alpha_{t} h_{0} .
$$

The other features of this economy are exactly the same as for the economy with divisible labor. These include the technology and the description of the stochastic process for the technology shock. These features are described by eqs. (1) through (4).

Firms in the economy, as in the previous economy, will want to employ labor up to the point where $f_{h}\left(\lambda_{t}, k_{t}, h_{t}\right)=w_{t}$. However, due to the fact that lottery contracts are being traded, households are not paid for the time they actually spend working, but are instead paid for the expected amount of time spent working. This implies that each worker is paid as if he worked $h_{t}$ [as defined in (10)] rather than for the amount he actually does work. Therefore, the budget constraint of a typical household differs from the budget constraint for the economy where labor is divisible (6) and is given by

$$
c_{t}+i_{t} \leq w_{t} \alpha_{t} h_{0}+r_{t} k_{t}
$$

Thus, the problem solved by a typical household is

$$
\max E \sum_{t=0}^{\infty} \beta^{t} U\left(c_{t}, \alpha_{t}\right), \text { given } k_{0} \text { and } \lambda_{0},
$$

subject to

(11) and (3).

This problem is equivalent to the problem solved by households in a slightly different economy where agents trade man-hours and actuarially fair insurance contracts, rather than the type of contracts traded in the economy studied here. In this alternative economy, which is described in more detail in the appendix, households only get paid for the time they actually spend working. However, if a household has purchased unemployment insurance, it will receive compensation if the lottery determines that the household does not work. In the appendix it is shown that households will choose to insure themselves fully. Therefore, in equilibrium, the households will have full unemployment insurance, just like the households populating the economy described in this section. This implies that the equilibrium allocations for these two economies are the same. 
The following is the representative agent's problem that must be solved to derive the equilibrium decision rules and laws of motion:

$$
\max E \sum_{t=0}^{\infty} \beta^{t} U\left(c_{t}, \alpha_{t}\right), \text { given } k_{0} \text { and } \lambda_{0},
$$

subject to

$$
(1)-(4),(10) \text { and ' } \varepsilon_{t} \sim \text { c.d.f. } F \text {. }
$$

Like problem (7), this is a standard concave discounted dynamic programming problem. The state of the economy in period $t$ is described by $k_{1}$ and $\lambda_{t}$. The decision variables are $\alpha_{t}, c_{t}$, and $i_{t}$.

A key property of this economy is that the elasticity of substitution between leisure in different periods for the 'representative agent' is infinite. To understand this result, first substitute $h_{t}=1-l_{t}$ into (10) and solve for $\alpha_{t}$. After substituting this expression for $\alpha$, into ( 9 ) one obtains the following utility function for the representative agent (ignoring the constant term):

$$
U\left(c_{t}, l_{t}\right)=\log c_{t}+B l_{t},
$$

where $B=-A\left(\log \left(1-h_{0}\right)\right) / h_{0}$. Since this utility function is linear in leisure it implies an infinite elasticity of substitution between leisure in different periods. This follows no matter how small this elasticity is for the individuals populating the economy. Therefore, the elasticity of substitution between leisure in different periods for the aggregate economy is infinite and independent of the willingness of individuals to substitute leisure across time. ${ }^{14}$

\section{Solution method and calibration}

The problems (7) and (13) are not in the class of problems for which it is possible to solve analytically for decision rules. This special class of problems includes those with quadratic objectives and linear constraints, as well as some other structures. For this reason, approximate economies are studied for which the representative agent's problem is linear-quadratic [see Kydland and Prescott (1982)]. It is then possible to obtain explicit decision rules for these approximate economies.

By making appropriate substitutions, one can express problems (7) and (13) as dynamic optimization problems with decision variables $i$, and $h$, and state variables $\lambda_{t}$ and $k_{t}$. The constraints for these problems are linear although the

\footnotetext{
${ }^{14}$ The fact that in this type of model the representative agent's utility function is linear in leisure was originally shown by Rogerson (1984) for his model. This result depends, however, on the utility function being additively separable across time.
} 
objective functions are non-linear. For each of these problems, Kydland and Prescott's procedure is used to construct a quadratic approximation of the objective function to be accurate in a neighborhood of the steady state for the appropriate model after the technology shock has been set equal to its unconditional mean of one. ${ }^{15}$ The reader may consult Kydland and Prescott (1982) for details on the algorithm used for forming these approximations. ${ }^{16}$

To actually compute these quadratic approximations, solve for an equilibrium, and generate artificial time series, it is necessary to choose a distribution function, $F$, and specific parameter values for $\theta, \delta, \beta, A, \gamma$, and $h_{0}$. Kydland and Prescott $(1982,1984)$ follow a methodology for choosing parameter values based on evidence from growth observations and micro studies. This methodology will also be followed here. In fact, since they study a similar economy, some of the above parameters $(\theta, \delta, \beta)$ also appear in their model. This enables me to draw on their work in selecting values for these parameters, thereby making it easier to compare the results of the two studies.

The parameter $\theta$ corresponds to capital's share in production. This has been calculated using U.S. time series data by Kydland and Prescott $(1982,1984)$ and was found to be approximately 0.36 . The rate of depreciation of capital, $\delta$, is set equal to 0.025 which implies an annual rate of depreciation of 10 percent. Kydland and Prescott found this to be a good compromise given that different types of capital depreciate at different rates. The discount factor, $\beta$, is set equal to 0.99 , which implies a steady state annual real rate of interest of four percent.

The parameter $A$ in the utility function (5) is set equal to 2 . This implies that hours worked in the steady state for the model with divisible labor is close to $1 / 3$. This more or less matches the observation that individuals spend $1 / 3$ of

${ }^{15}$ Let the steady states for the certainty version of these models be denoted by the variable's symbol without any subscript. Eq. (3) implies that investment in the steady state is given by $i=\delta k$. Expressions for $k$ and $h$ can be determined by deriving the Euler equations for the appropriate represcntative agent problem and setting $h_{t}=h, k_{t}=k$, and $i_{t}=i=\delta k$ for all $t$. For both economies, the steady state capital stock is given by

$$
k=[(\rho+\delta) / \theta]^{1 /(\theta-1)} h \text { where } \rho=(1 / \beta)-1 .
$$

Hours worked in the steady state for the economy with divisible labor is given by $h=(1-\theta) \times$ $(\rho+\delta) /[3(\rho+\delta)-\theta(\rho+3 \delta)]$; and for the economy with indivisible labor, $h=(1-\theta)(\rho+\delta) /$ $[\psi(\rho+\delta-\theta \delta)]$ where $\psi=-A\left[\log \left(1-h_{0}\right)\right] / h_{0}$.

${ }^{16} \mathrm{Kydland}$ and Prescott's method for approximating this problem requires choosing a vector of average deviations, $z \in \mathbf{R}^{4}$, which determines the size of the neighborhood around the steady state within which the approximation is accurate. The four components of $z$ are average deviations from trend of the four variables, $x_{t}=\left(\lambda_{t}, k_{1}, i_{t}, h_{t}\right)$, as found in U.S. time series data. This implies that along those dimensions where there is more variability, the approximation will be accurate in a larger neighborhood around the steady state $(\bar{x})$. For the exercise carried out in this paper $\left\{z_{i} / \bar{x}_{i}\right\}_{i-1}^{4}=(0.012,0.006,0.08,0.017)$, reflecting the average standard deviations of these series as reported in the next section. Although attention was paid to specifying this vector in a reasonable way, it turas out that the results are not altered when the $z_{i}$ components are decreased by a factor of ten. 
their time engaged in market activities and $2 / 3$ of their time in non-market activities.

To determine the parameter $h_{0}$, I set the expressions for hours of work in the steady state for the two models equal to each other. Since steady state hours worked in the model with divisible labor is fully determined by the parameters $\theta, \delta, A$, and $\beta$ for which values have already been assigned (see footnote 15), it is possible to solve for $h_{0}$. This implies a value for $h_{0}$ of 0.53 .

The distribution function $F$ along with the parameter $\gamma$ determine the properties of the technology shock, $\lambda_{t}$. The distribution of $\varepsilon_{t}$ is assumed to be $\log$ normal with mean $(1-\gamma)$, which implies that the unconditional mean of $\lambda_{\text {, }}$ is 1 . The parameter $\gamma$ is set equal to 0.95 which is consistent with the statistical properties of the production function residual. ${ }^{17}$ The standard deviation of $\varepsilon_{t}, \sigma_{\varepsilon}$, is difficult to measure from available data since this number is significantly affected by measurement error. A data analysis suggests that $\sigma_{\varepsilon}$ could reasonably be expected to lie in the interval $[0.007,0.01]$. A value of 0.007 , for example, would imply that a little over half of the variability in $\varepsilon_{f}$ is being attributed to measurement error, which is probably not unreasonable. The actual value used for the simulations in this paper is 0.00712 . This particular value was chosen because it implies that the mean standard deviation of output for the economy with indivisible labor is equal to the standard deviation of GNP for the U.S. economy (see next section).

All parameters of the two models have now been determined. We are now ready to study and compare the statistical properties of the time series generated by these two models.

\section{Results}

For the purposes of this study, the statistical properties of the economies studied are summarized by a set of standard deviations and correlations with output that are reported in table 1.

The statistics for the U.S. economy are reported in the first two columns of the table. Before these statistics were calculated, the time series were logged and deviations from trend were computed. Detrending was necessary because the models studied abstract from growth. The data were logged so that standard deviations can be interpreted as mean percentage deviations from

\footnotetext{
${ }^{17}$ The production function residual is measured, using U.S. time series, by $\log \lambda_{t}=\log y_{t}-\theta \log k_{t}-(1-\theta) \log h_{t}$,
}

where data on GNP, capital stock (nonresidential equipment and structures), and hours worked is obtained from a standard econometric data base. The first-order autocorrelation coefficient for $\lambda_{1}$ is about 0.95 , indicating high serial correlation in this series. The parameter $\theta$ was assumed to be equal to 0.36 for calculating this residual. A more detailed study of the statistical properties of this technology shock is planned but has not yet been carried out. 
Table 1

Standard deviations in percent (a) and correlations with output (b) for U.S. and artificial economies.

\begin{tabular}{|c|c|c|c|c|c|c|}
\hline \multirow[b]{2}{*}{ Scries } & \multicolumn{2}{|c|}{$\begin{array}{l}\text { Quarterly U.S. time series } \\
(55,3-84,1)\end{array}$} & \multicolumn{2}{|c|}{$\begin{array}{l}\text { Economy with } \\
\text { divisible labor }\end{array}$} & \multicolumn{2}{|c|}{$\begin{array}{l}\text { Economy with } \\
\text { indivisible labor }\end{array}$} \\
\hline & (a) & (b) & (a) & (b) & (a) & (b) \\
\hline Output & 1.76 & 1.00 & $1.35(0.16)$ & $1.00(0.00)$ & $1.76(0.21)$ & $1.00(0.00)$ \\
\hline Consumption & 1.29 & 0.85 & $0.42(0.06)$ & $0.89(0.03)$ & $0.51(0.08)$ & $0.87(0.04)$ \\
\hline Investment & 8.60 & 0.92 & $4.24(0.51)$ & $0.99(0.00)$ & $5.71(0.70)$ & $0.99(0.00)$ \\
\hline Capital stock & 0.63 & 0.04 & $0.36(0.07)$ & $0.06(0.07)$ & $0.47(0.10)$ & $0.05(0.07)$ \\
\hline Hours & 1.66 & 0.76 & $0.70(0.08)$ & $0.98(0.01)$ & $1.35(0.16)$ & $0.98(0.01)$ \\
\hline Productivity & 1.18 & 0.42 & $0.68(0.08)$ & $0.98(0.01)$ & $0.50(0.07)$ & $0.87(0.03)$ \\
\hline
\end{tabular}

\footnotetext{
"The U.S. time serics used are real GNP. total consumption expenditures, and gross private domestic investment (all in 1972 dollars). The capital stock series includes nonresidential equipment and structures. The hours series includes total hours for persons at work in non-agricultural industries as derived from the Currem Population Survey: Productivity is output divided by hours. All series are seasonally adjusted. logged and detrended.

bThe standard deviations and correlations with output are sample means of statistics computed for each of 100 simulations. Each simulation consists of 115 periods, which is the same number of periods as the U.S. sample. The numbers in parentheses are sample standard deviations of these statistics. Before computing any statistics each simulated time series was logged and detrended using the same procedure used for the U.S. time series.
}

trend. The 'detrending' procedure used is the method employed by Hodrick and Prescott (1980). ${ }^{18}$

Since much of the discussion in this section centers on the variability of hours worked and productivity (output divided by hours worked), some discussion of the hours series is appropriate. The time series for hours worked used in constructing these statistics is derived from the Current Population Survey, which is a survey of households. This series was chosen in preference to the other available hours series which is derived from the establishment survey. The hours series based on the household survey is more comprehensive than

${ }^{18}$ This method involves choosing smoothed values $\left\{s_{1}\right\}_{r-1}^{T}$ for the series $\left\{x_{f}\right\}_{r-1}^{T}$ which solve the following problem:

$$
\min \left\{(1 / T) \sum_{t=1}^{T}\left(x_{t}-s_{t}\right)^{2}+(\lambda / T) \sum_{t=2}^{T-1}\left[\left(s_{t+1}-s_{t}\right)-\left(s_{t}-s_{t-1}\right)\right]^{2}\right\},
$$

where $\lambda>0$ is the penalty on variation, where variation is measured by the average squared second difference. A larger value of $\lambda$ implies that the resulting $\left\{s_{t}\right\}$ series is smoother. Following Prescott (1983), I choose $\lambda=1600$. Deviations from the smooth series are formed by taking $d_{1}=x_{t}-s_{t}$.

This method is used in order to filter out low frequency fluctuations. Although other methods (spectral techniques, for example) are available, this method was chosen because of its simplicity and the fact that other methods lead to basically the same results [see Prescott (1983)]. 
the establishment series since self-employed workers and unpaid workers in family-operated enterprises are included. Another advantage is that the household series takes into account only hours actually worked rather than all hours paid for. That is, it doesn't include items such as paid sick leave. A disadvantage is that the household series begins in the third quarter of 1955, which prevented me from using data over the entire post-war period.

Sample distributions of the summary statistics describing the behavior of the artificial economies were derived using Monte Carlo methods. The model was simulated repeatedly to obtain many samples of artificially generated time series. Each sample generated had the same number of periods (115) as the U.S. time series used in the study. Before any statistics were computed, the data were logged and the same filtering procedure applied to the U.S. data was applied to these time series. One hundred simulations were performed and sample statistics were calculated for each data set generated. The sample means and standard deviations of these summary statistics are reported in the last four columns of table 1.

When comparing the statistics describing the two artificial economies, one discovers that the economy with indivisible labor displays significantly larger fluctuations than the economy with divisible labor. This shows that indivisible labor increases the volatility of the stochastic growth model for a given stochastic process for the technology shock. In fact, it is necessary to increase $\sigma_{\varepsilon}$ by 30 percent (from 0.00712 to 0.00929 ) in order to increase the standard deviation of output for the divisible labor economy so that it is equal to the standard deviation of GNP for the actual economy, which is 1.76. It is still the case that 0.00929 is in the interval suggested by the data (see paragraph on measuring $\sigma_{\varepsilon}$ in the previous section). However, since it is likely that there is significant measurement error in our empirical estimate of the production function residual, one should prefer the lower value of $\sigma_{\varepsilon}$.

Another conclusion drawn from studying this table is that the fluctuations in most variables are larger for the actual economy than for the indivisible labor economy. It is my view that most of this additional fluctuation (except in the case of the consumption series) is due to measurement error. Work in progress by the author attempts to correct for measurement error in the hours series (and hence some of the measurement error in the productivity series). ${ }^{19}$ Preliminary findings seem to suggest that the above hypothesis is correct. In addition, the fact that the consumption series fluctuates much more in the actual economy than in the artificial economy can probably be explained by the fact that nothing corresponding to consumer durables is modeled in the economies studied here.

\footnotetext{
${ }^{19}$ The work referred to is a chapter of my dissertation. Copies will soon be available upon request.
} 
Perhaps the most significant discovery made by examining table 1 is that the amount of variability in hours worked relative to variability in productivity is very different for the two model economies. This relative variability can be measured by the ratio of the standard deviation in hours worked to the standard deviation in productivity. For the economy with indivisible labor, this ratio is 2.7 , and for the economy without this feature the ratio is not significantly above $1 .^{20}$ For the U.S. economy the ratio is equal to 1.4 , which is between these two values.

As explained in the introduction, accounting for the large variability in hours worked relative to productivity has been an open problem in equilibrium business cycle theory. Kydland and Prescott (1982) study a version of the stochastic growth model where labor is divisible and the utility function of individuals is non-time-separable with respect to leisure. This non-time-separability property is introduced to make leisure in different periods better substitutes. However, this feature enables these authors to report a value for this ratio of only 1.17 , which is still much too low to account for the fluctuations found in U.S. data.

On the other hand, the economy with indivisible labor studied here has exactly the opposite problem Kyland and Prescott's model has. The ratio implied by this model is much larger than the ratio implied by the data. However, this should not be surprising. In fact, it would be bothersome if this were not the case. After all, we do observe some adjustment along the intensive margin in the real world. Examples include workers who work overtime in some periods and not in others or salesmen who work a different number of hours each day. Since indivisible labor implies that all fluctuations are along the extensive margin, one would expect - even without looking at statistics calculated from the data - that the ratio discussed above should be somewhere between the one implied by an indivisible labor economy and a divisible labor economy.

\section{Conclusion}

A dynamic competitive equilibrium economy with indivisible labor has been constructed with the aim of accounting for standard deviations and correlations with output found in aggregate economic time series. Individuals in this economy are forced to enter and exit the labor force in response to technology shocks rather than simply adjusting the number of hours worked while remaining continuously employed. Therefore, this is an equilibrium model which exhibits unemployment (or employment) fluctuations in response to aggregate shocks. Fluctuations in employment seem important for fluctuations

\footnotetext{
${ }^{20}$ This ratio is still not significantly different from one even when $\sigma_{\mathrm{E}}$ is increased to 0.00929 .
} 
in hours worked over the business cycle since most of the variability in total hours is unambiguously due to variation in the number employed rather than hours per employed worker.

An important aspect of this economy is that the elasticity of substitution between leisure in different periods for the aggregate economy is infinite and independent of the elasticity of substitution implied by the individuals' utility function. This distinguishes this model, or any Rogerson (1984) style economy, from one without indivisible labor. These include the model presented in section 3.1 and the economy studied by Kydland and Prescott (1982). In these divisible labor models, the elasticity of substitution for the aggregate economy is the same as that for individuals.

This feature enables the indivisible labor economy to exhibit large fluctuations in hours worked relative to fluctuations in productivity. Previous equilibrium models of the business cycle, which have all assumed divisible labor, have been unsuccessful in accounting for this feature of U.S. time series. This is illustrated in this paper by showing that a model with divisible labor fails to exhibit large fluctuations in hours worked relative to productivity while the model with indivisible labor displays fluctuations in hours relative to productivity which are much larger than what is observed. This seems to indicate that a model which allowed for adjustment along both the extensive margin as well as the intensive margin would have a good chance for successfully confronting the data.

In conclusion, this study demonstrates that non-convexities such as indivisible labor may be important for explaining the volatility of hours relative to productivity even when individuals are relatively unwilling to substitute leisure across time. They are also useful for increasing the size of the standard deviations of all variables relative to the standard deviation of the technology shock. Therefore, a smaller size shock is sufficient for explaining business cycle fluctuations than was true for previous models such as Kydland and Prescott's (1982). In addition, these non-convexities make it possible for an equilibrium model of the business cycle to exhibit fluctuations in employment. Therefore, non-convexities will inevitably play an important role in future equilibrium models of the cycle.

\section{Appendix: A market for unemployment insurance}

The purpose of this appendix is to show that the equilibrium of the economy presented in section 3.2 is equivalent to the equilibrium of an economy where labor is still indivisible but households are able to purchase any amount of unemployment insurance they choose. In the original economy, agents are assumed to buy and sell contracts which specify a probability of working in a given period as opposed to buying and selling hours of work. A lottery determines which households must work and which do not. A household is 
paid according to the probability that it works, not according to the work it actually does. In other words, the firm is automatically providing full unemployment insurance to the households.

In this appendix, households choose a probability of working each period and a lottery is held to determine which households must work, just as in the original economy. Also, preferences, technology, and the stochastic structure are exactly the same as for the original model. However, this economy is different in that households only get paid for the work they actually do - unemployed individuals get paid nothing by the firm. But, the household does have access to an insurance market which preserves the complete markets aspect of the original model. It is shown below that the equilibrium of this economy is equivalent to that of the original economy since individuals will choose to be fully insured in equilibrium. This is shown by proving that the problem solved by households is the same as the problem solved by households (12) in the original model.

The problem solved by the households can be described as follows: Each period, households choose a probability of working, $\alpha_{t}$, a level of unemployment compensation, $y_{t}$, and consumption and investment contingent on whether the household works or not, $c_{s t}$ and $i_{s t}(s=1,2)$. These are chosen to solve the following dynamic programming problem (primes denote next period values):

$$
\begin{aligned}
\max V(\lambda, K, k)= & \alpha\left\{u\left(c_{1}\right)+\nu\left(1-h_{0}\right)+\beta \mathrm{E} V\left(\lambda^{\prime}, K^{\prime}, k_{1}^{\prime}\right)\right\} \\
& +(1-\alpha)\left\{u\left(c_{2}\right)+\nu(1)+\beta \mathrm{E} V\left(\lambda^{\prime}, K^{\prime}, k_{2}^{\prime}\right)\right\}
\end{aligned}
$$

subject to

$$
\begin{aligned}
& c_{1}+i_{1} \leq w(\lambda, K) h_{0}+r(\lambda, K) k-p(\alpha) y, \\
& c_{2}+i_{2} \leq y+r(\lambda, K) k-p(\alpha) y, \\
& k_{s}^{\prime}=(1-\delta) k+i_{s}, \quad s=1,2 .
\end{aligned}
$$

The function $V(\lambda, K, k)$ is the value function which depends on the household's state. The state vector includes the capital owned by the household, plus the economy wide state variables $\lambda$ and $K$, where $K$ is the per capita capital stock. $^{21}$ The functions $w(\lambda, K)$ and $r(\lambda, K)$ are the wage rate and rental rate

\footnotetext{
${ }^{21}$ Since we are allowing households to choose any level of unemployment insurance they wish, we have to allow for the heterogeneity that may come about because different households will have different income streams. This is why the distinction is made between the per capita capital stock, $K$, and the households accumulated capital stock, $k$. However, this heterogeneity will disappear in equilibrium since all housebolds will choose full insurance, so $K=k$ in equilibrium.
} 
of capital respectively, and $p(\alpha)$ is the price of insurance, which is a function of the probability that the household works. Also, since individuals' preferences are the same as for the original model, $u(c)=\log c$ and $\nu(l)=A \log l$.

The insurance company in this economy maximizes expected profits which are given by $p(\alpha) y-(1-\alpha) y$. That is, the firm collects revenue $p(\alpha) y$ and pays $y$ with probability $1-\alpha$. To guarantee that profits are bounded, $p(\alpha)=$ $(1-\alpha)$. Therefore, the price the household must pay for insurance equals the probability that the household will collect on the insurance.

One can now substitute this expression for $p$ into constraints (A.2) and (A.3). After eliminating the constraints by substituting out $i_{s}$ and $c_{s}(s=1,2)$, one can write the following first-order necessary conditions for $k_{s}^{\prime}$ and $y$ :

$$
\begin{aligned}
& u^{\prime}\left(c_{s}\right)=\beta \mathrm{E} V_{k^{\prime}}\left(\lambda^{\prime}, K^{\prime}, k_{s}^{\prime}\right), \quad s=1,2, \\
& u^{\prime}\left(c_{1}\right)=u^{\prime}\left(c_{2}\right) .
\end{aligned}
$$

Eq. (A.6) implies, given the strict concavity of $u$, that $c_{1}=c_{2}$. This plus eq. (A.5) imply that $k_{1}^{\prime}=k_{2}^{\prime}$. This, in turn, implies that $i_{1}=i_{2}$. Therefore, the left-hand sides of eqs. (A.2) and (A.3) are identical. Since these constraints will be binding in equilibrium, $y$ will be chosen so that the right-hand sides are equal as well. This means that $y=w h_{0}$ in equilibrium. That is, households will choose to insure themselves fully. This has the implication that all households will choose the same sequence of capital stocks, so $K=k$.

Substituting these results into the household's optimization problem (A.1) yields the following problem: Households choose $c, i, k^{\prime}$, and $\alpha$ to

$$
\max V(\lambda, k)=u(c)+\alpha \nu\left(1-h_{0}\right)+(1-\alpha) \nu(1)+\beta \mathrm{E} V\left(\lambda^{\prime}, k^{\prime}\right),
$$

subject to

$$
\begin{aligned}
& c+i \leq \alpha w(\lambda, k) h_{0}+r(\lambda, k) k, \\
& k^{\prime}=(1-\delta) k+i .
\end{aligned}
$$

This problem is identical to problem (12). Therefore, the equilibrium allocation for the original economy, where the firm provides full unemployment insurance to workers by assumption, is equivalent to the equilibrium allocation for an economy where households get paid by the firm only for work done but have access to a risk-neutral insurance market. This result, of course, depends crucially on the probability $\alpha$ being publicly observable and the contract being enforceable. That is, it must be the case that the agent announces the same $\alpha$ to both the firm and the insurance company, and if the agent loses the lottery (that is, has to work) this is known by all parties. For example, this result 
would not hold if $\alpha$ depended on some underlying choice variable like effort that was not directly observed by the insurance company. In this case a difficult moral hazard problem would arise.

\section{References}

Altonji, J.G., 1984, Intertemporal substitution in labor supply: Evidence from micro data, Unpublished manuscript (Columbia University, New York).

Ashenfelter, O., 1984, Macroeconomic analyses and microeconomic analyses of labor supply. Carnegie-Rochester Conference Series on Public Policy 21, 117-156.

Bertsekas, D.P., 1976, Dynamic programming and stochastic control (Academic Press, New York).

Coleman, T.S., 1984, Essays on aggregate labor market business cycle fluctuations, Unpublished manuscript (University of Chicago, Chicago, IL).

Debreu, G., 1954, Valuation equilibrium and Pareto optimum, Proceedings of the National Academy of Sciences 40, 588-592.

Heckman, J.J., 1984, Comments on the Ashenfelter and Kydland papers, Carnegie-Rochester Conference Series on Public Policy 21, 209-224.

Heckman, J.J. and T.E. MaCurdy, 1980, A life cycle model of female labor supply, Review of Economic Studies 47, 47-74.

Hodrick, R.J. and E.C. Prescott, 1980, Post-war U.S. business cycles: An empirical investigation, Working paper (Carnegie-Mellon University, Pittsburgh, PA).

Kydland, F.E. and E.C. Prescott, 1982, Time to build and aggregate fiuctuations, Econometrica 50, 1345-1370.

Kydland, F.E. and E.C. Prescott, 1984. The workweek of capital and labor, Unpublished manuscript (Federal Reserve Bank of Minneapolis, Minneapolis, MN).

Lucas, R.E.. Jr., 1977, Understanding business cycles, Carnegie-Rochester Conference Series on Public Policy 5, 7-29.

Lucas, R.E., Jr. and E.C. Prescott, 1971, Investment under uncertainty, Econometrica 39, 659-681.

Lucas, R.E., Jr., E.C. Prescott and N.L. Stokey, 1984, Recursive methods for economic dynamics, Unpublished manuscript (University of Minnesota, Minneapolis, MN).

MaCurdy. T.E., An empirical model of labor supply in a life-cycle setting, Journal of Political Economy 89, 1059-1085.

Rogerson, R., Indivisible labour, lotteries and equilibrium, Unpublished manuscript (University of Rochester, Rochester, NY).

Prescott, E.C.. Can the cycle be reconciled with a consistent theory of expectations? or a progress report on business cycle theory, Unpublished manuscript (Federal Reserve Bank of Minneapolis, Minneapolis, MN).

Solow, R.M., Technical change and the aggregate production function, The Review of Economics and Statistics 39, 312-320. 